\title{
Radiation Exposure of Leukemia Blood Samples and Its Impacts on the Density of RBC, WBC, and PLT: In Vitro
}

\author{
Asaad H. Ismail ${ }^{1,2}$, Muhamad A. Hamad ${ }^{1,2}$, Edrees M. T. Harki ${ }^{1,2}$ \\ ${ }^{1}$ Research Group of Medical Physic, Physics Department, Education College, Salahaddin University, Erbil, Iraq \\ ${ }^{2}$ Scientific Department, Salahaddin University, Erbil, Iraq \\ Email: asadhawlery@hotmail.com
}

Received May 28, 2012; revised July 10, 2012; accepted July 23, 2012

\begin{abstract}
Complete blood counts were analyzed for 12 samples (six males \& six females: Ages 15 - 40 years) of leukemia blood Samples for different dose rate and time of exposure using a Radium-226 source. Thus, an optimum time of exposure and exposure dose rate has improved for leukemia blood samples. Blood samples fractionated and placed in plastic wills, and melodic Coulter used to analysis exposed leukemia blood samples before and after exposure. Exposure technique involving CR-39 nuclear track detector and radiation survey dosimeter were used to estimate the alpha particle density incident on the blood samples and the exposed dose rate, respectively. In the first part, density of the accumulation of alpha particle on the surface of leukemia blood samples, and on the surface of CR-39NTDs varies exponentially with the exposed dose rate. This depends on the restricted energy loss of the incident alpha particles and target density. Assess an optimum time of exposure dose rate $(1100 \mu \mathrm{Sv} / \mathrm{h})$ was the second objective. This depended on the changes in the blood components (PLT, WBC, and RBC) due to irradiation occurred for different durations of irradiation, and the duration of irradiation that influenced the leukemia blood samples (1 Male, 16 years and one Female 17 years) in this research was five minutes. Changes in the density of PLT, WBC, and RBC for leukemia blood samples and for different male (five males) and female (five females) was the third part of this research. It was found that the changes were variables due to the exposed dose rate. Optimum exposed dose rate to make more effects on the cancer cells for the leukemia blood samples began at the radiation dose rate of $43.25 \pm 1.206 \mu \mathrm{Sv} / \mathrm{h}$ for both; male and female relatively, and this due to chromosomal aberration of the exposed cells. Finally, comparison study with the healthy blood samples has been investigated. More details are listed and clarified in the tables and figures of this paper.
\end{abstract}

Keywords: Radiation Dose; Alpha Particle; RBC; WBC; PLT; Leukemia; CR-39NTDs

\section{Introduction}

Disease of Leukemia is often called as the blood cancer. It is a malignant condition that affects the immature forming of the blood cells in the bone marrow. Just like any other type of cancer, leukemia is a result from the somatic mutations of the DNA that activate or deactivate the tumor suppressor genes. These may occur suddenly or as a result of being exposed to radiation or carcinogenic substances that are influenced by the genetic factor [1]. Radiation exposure can be acute or chronic, and the severity of symptoms depends on many factors, such as total dose, dose rate, distribution of dose, susceptibility of the person to radiation, and the type of organs (more radiosensitive tissues) [2,3]. Generally, high linear energy transfer (LET) radiation (alpha particles and fission fragments) is more efficient in inducing biological damage than low LET radiation (gamma ray, X-rays, and $\beta$-particles) [4]. This is because most of the incident energy will be deposited within a short distance, causing dense ionization in the trajectory [5-7]. Ionizing radiation breaks down and destabilizes the molecules, and this is particularly true for biomolecules, including DNA. DNA can suffer slight damage that can be repaired. Alpha particle is a heavy nuclear particle and is denoted by the Greek alphabet, $\alpha$. It has a highly ionization form of particle radiation, and exhibits low penetration and velocity of the matter. Thus, it loses most of its energy in a short distance. Hematology studies in the field of radiation have played an active role to estimating the exposure to ionizing radiation, as it increases the number of chromosomal aberrations in human blood lymphocytes [5]. Deposition of the alpha particles into the tissues and cells may cause damage (temporary and permanent), depending on the time of exposure, energy of the alpha particles, and quantity of the absorbed dose. Thus, studies on the risks of radiation have been carried out for a long time and research on the techniques is novel [6].

High LET radiation (Alpha particles) is more efficient in inducing biological damage than low LET radiation $(\gamma-$ 
and X-rays, $\beta$-particles) because all the energy is deposited within a short distance, causing dense ionization in the trajectory [8].

The importance of analyzing the effects of alpha radiation at the cellular level is its implication in diverse areas, such as nuclear medicine [9], nuclear industries [10] and biomedicine [11], increasing the risk of occupational and accidental exposure. The use of some alpha emitter radionuclides, such as $226 \mathrm{Ra}$ and $241 \mathrm{Am}$, in nuclear medicine is due to their low tissue penetration, with reduced toxicity to neighboring tissues [12]. In the previous work [6], $226 \mathrm{Ra}$ use as a pure source of high-energy alpha particles is of particular interest. And the effects of deposition of alpha particles onto the healthy cells of human blood samples for different exposure dose and time of exposure have been investigated using the alpha irradiation collimator being in direct contact with the blood sample. Present work includes effects of several exposure dose on the cancer cells of leukemia blood samples. Thus, an optimum time of exposure and exposure dose rate are the two main objectives of this study. On the other hand, a comparison results between healthy and leukemia blood samples be considered.

\section{Interaction of Alpha Particles with the Blood Cells}

Alpha particles are often referred to as instantly ionizing radiation. When leukemia blood samples expose to the source of alpha particles, alpha particle interacted directly with the external electrons of the constituent atoms, and if they supply enough energy, they can knock the outer electrons away from the atoms [13]. The product of such an event is a free electron and a positively charged ion, and this process called ionization of the blood cells. The biological effect begins with the ionization of atoms. The mechanism by which radiation causes damage to human tissue is through ionization of atoms in the material. Ionizing radiation absorbed by human tissues has sufficient energy to remove electrons from the atoms that make up the molecules of the tissue [14]. When the electron shared by two atoms to form a molecular bond is dislodged by ionizing radiation, the bond is broken, and thus the molecule falls apart $[13,15]$. This is a basic model for understanding radiation damage. When ionizing radiation interacts with cells, it may or may not strike a critical part of the cell. It is considered that the chromosomes are the most critical part of the cell, because they contain the genetic information and instructions required for the cell to perform its function and make copies of it for reproduction purposes. In addition, there are very effective repair mechanisms at work constantly, which repair cellular damage, including chromosome damage.

Alpha particles are helium nuclei that deposit DNAdamaging energy along their track, which is $100-1000$ times greater than that of the conventionally used betaparticle emitting radionuclides for targeted therapy. The damage caused by alpha particles is predominately doublestranded DNA breaks, severe enough to be irreparable. This signifies that a small number of tracks through a cell nucleus can sterilize a cell and that, as the damage is largely unrectifiable, alpha-particle radiation is not susceptible to resistance as seen with external radiotherapy [16].

The effective grade of the ionization of incident alpha particles depends on its energy and time of exposure, and can cause an excitation of molecules in blood, resulting in their vibration and ionization. An immediate decrease in the lymphocytes may not spontaneously affect the other mature blood cells. However, all blood cells are constantly replaced by new ones. If these replacements fail because of the damage to the bone marrow, the population of white blood cells will drop in a few days after exposure, sometimes followed by a rather slow decrease in the red blood cells. Red blood cells live longer than white blood cells, and hence; they are replaced more gradually, and thus the effect is seen somewhat later. It was demonstrated in 1904 that immature cells and rapidly dividing cells are more sensitive to ionizing radiation than mature cells. In particular, cancerous growths, in which cells proliferate rapidly, are more radiosensitive than healthy tissue a fact that contributes to the effectiveness of radiation therapy [7,17].

\section{Blood Components (PLT, WBC \& RBC)}

Blood is a liquid tissue. Suspended in the watery plasma are seven types of cells and cell fragment; Red blood cells (RBCs), Platelets (PLT), and five kinds of white blood cells (WBCs) [18,19]. If one takes a sample of blood, treats it with an agent to prevent clotting, and spins it in a centrifuge. Red blood cells are the most numerous types in the blood; average $7 \mu \mathrm{m}$ in diameter. Women average about 4.8 million of these cells per cubic millimetre $\left(\mathrm{mm}^{3}\right.$; which is the same as a micro-litter; $\left.\mu \mathrm{l}\right)$ of blood. And men average about $5.4 \times 106$ per $\mu$ l. These values can vary over quite a range depending on such factors as health and altitude. RBC precursors mature in the bone marrow closely attached to a macrophage. They manufacture hemoglobin until it accounts for some $90 \%$ of the dry weight of the cell (see Table 1) [12]. The ionization is more effective in blood than other tissues. They live about 120 days and then are ingested by phagocytic cells in the liver and spleen. Most of the iron in their hemoglobin is reclaimed for reuse. Some 3 million RBCs die and are scavenged by the liver each second. White Blood Cells are much less numerous than red (the ratio between the two is around 1:700). There are several kinds of lymphocytes, each with different functions to perform. The most common types of lymphocytes are B lymphocytes ("B cells"). 
Table 1. Materials with the fraction by weight (mass per percent) of the blood 12.

\begin{tabular}{cccc}
\hline Materials & Fraction by weight & Materials & $\begin{array}{c}\text { Fraction by } \\
\text { weight }\end{array}$ \\
\hline Hydrogen & 0.101866 & Phosphorus & 0.00035 \\
Carbon, amorphous & 0.10002 & Sulfur & 0.00185 \\
Nitrogen & 0.02964 & Chlorine & 0.00278 \\
Oxygen & 0.759414 & Potassium & 0.00163 \\
Sodium & 0.00185 & Calcium & 0.00006 \\
Magnesium & 0.00004 & Iron & 0.00046 \\
Silicon & 0.00003 & Zinc & 0.00001 \\
\hline
\end{tabular}

\section{Materials and Research Methodology}

\subsection{Materials}

\subsubsection{Patients and Blood Sample}

Blood samples were obtained from 12 patients of Leukaemia (six males; six females) (The ages ranged between 16 - 40 years old), with history of chemotherapy. This project was evaluated and approved by the Physics department (radiation Lab.) and Nanakali hospital for blood diesis in Iraqi Kurdistan. About $7 \mathrm{ml}$ of blood was collected by venipuncture from each patient into heparinnised syringes. All samples were analyzed by blood analysis machine (Medonic), before and after irradiation.

\subsubsection{Irradiation Equipments and Materials}

Radium-226 (2 $\mu \mathrm{Ci})$ used as an irradiation source, CR-39 nuclear track detector (Parma-Italy) used to register tracks of incident alpha particles. Different lengths of irradiation collimators used to get several radiation dose rates. Survey dosimeter's type (Inspector Ext) used to measure an exposure dose rate. $6 \mathrm{~N}$ of chemical solution of $\mathrm{NaOH}$ and water bath used to chemical etching of CR-39NTDs.

\subsection{Experimental Procedures}

\subsubsection{Irradiation of CR-39NTDs}

The purpose of this part is to find and definition average dose rate, and density of an accumulation of alpha particles on the surface of the blood samples. Five pieces of the CR-39NTDs $(1.5 \mathrm{~cm} \times 1 \mathrm{~cm})$ irradiated by the source of radium source $\left({ }^{226} \mathrm{Ra}\right)$. The principle of irradiation depended on the distance between the source and the surface of CR-39NTDs using suitable irradiation collimators that fabricated in previous work [6]. Different length of an irradiation collimator given different expose dose rate $(\mu \mathrm{Sv} / \mathrm{hr})$, as shown in Figure 1(a). Figure 1(b) shows the mechanism of the measurements.
After irradiation of CR-39NTDs for 1minutes, this is a suitable time of irradiation that calibrated in previous work [6]. Procedures of chemical etching for each piece have done during suitable etching condition $6 \mathrm{~N} \mathrm{NaOH}$ at $70^{\circ} \mathrm{C}$ [6]. Scanning process for the registered alpha particles has done using optical microscope equipped with the software computer program. Tracks of incident alpha particles considered as a density of deposition alpha particles on $1 \mathrm{~cm}^{2}$. Average background radiation dose has measured $(0.101 \pm 0.002 \mu \mathrm{Sv} / \mathrm{hr})$, and it is considered out of data within the irradiation process. The irradiation system for sterile condition and physical dosimetry was supervised by the Department of Physics/Salahaddin University-Erbil.

\subsubsection{Irradiation of Leukaemia Blood Samples}

Blood samples were fractionated and irradiated with a ${ }^{226} \mathrm{Ra}$ source. Various exposure dose rates got for different source-distance at lab temperature $\left(25^{\circ} \mathrm{C} \pm 1{ }^{\circ} \mathrm{C}\right)$, and as reported in Table 2.

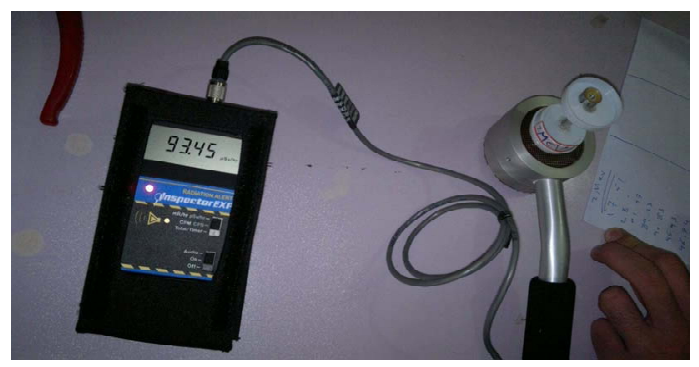

(a)

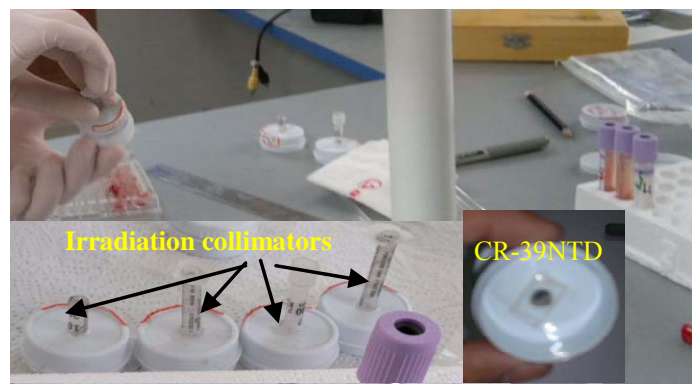

(b)

Figure 1. (a) Measurement of radiation dose for each irradiation collimator (b) irradiation collimators within irradiate of blood samples and CR-39NTDs.

Table 2. Exposed dose rate and energy of incident alpha particles for each source-detector distance.

\begin{tabular}{cc}
\hline $\begin{array}{c}\text { Source-detector } \\
\text { distance }(\mathrm{mm})\end{array}$ & $\begin{array}{c}\text { Exposure dose rate } \\
(\mu \mathrm{Sv} / \mathrm{hr})\end{array}$ \\
\hline 30 & $79.065 \pm 1.13$ \\
40 & $56.29 \pm 2.11$ \\
50 & $43.249 \pm 1.206$ \\
60 & $34.871 \pm 1.61$ \\
70 & $29.067 \pm 0.986$ \\
\hline
\end{tabular}


The source was calibrated using blood test wells .The apparatus was made of acrylic, since this material has a density approximately equal to that of water and similar to that of biological tissues. The short penetration trajectory of alpha particles was also considered since the average energy particle penetrates soft tissues to a depth of only $1 \mathrm{~mm}$ [6]. Blood samples were fractionated and placed in plastic wills, $1.7 \mathrm{~cm}$ high and $1.05 \mathrm{~cm}$ in diameter, forming a $0.5 \mathrm{ml}$ blood layer for irradiation.

\section{Results and Discussion}

Equivalent relationship between an exposure dose rates $(\mu \mathrm{Sv} / \mathrm{hr})$ and density of an accumulation of alpha particles on the surface of exposed leukemia blood samples has investigated. Average radiation doses recorded by the mentioned dosimeter represent the gamma, beta and alpha radiation doses, but the track density registered by CR-39 NTDs represents the tracks of alpha particles. Thus, exponential relationship between them was gotten, as shown in Figure 2. Fitting equation (Equation (1)) for the Figure 1 can be use to get track density of the incident alpha particles for any exposure dose for radium226 source.

Track density $\left(\right.$ track $/ \mathrm{cm}^{2}$ per 1 minute $)=a \exp ^{b(\mathrm{EDR})}(1)$ where $a$ and $b$ are the two constant equal to 33.969 and 0.4913 , respectively, and EDR is the value of exposure dose rate $(\mu \mathrm{Sv} / \mathrm{hr})$.

Exposure dose rate of $1100 \mu \mathrm{Sv} / \mathrm{hr}$ used to get an optimum time to expose leukemia blood samples for male and female, as shown in Figures 3 and 4. It is clear that the optimum and suitable time that requested to get sufficient changes in the components of leukemia blood samples for male and female was 5 minutes. This means that the exposed dose rate ( $\mu \mathrm{Sv} / \mathrm{hr})$ changed.

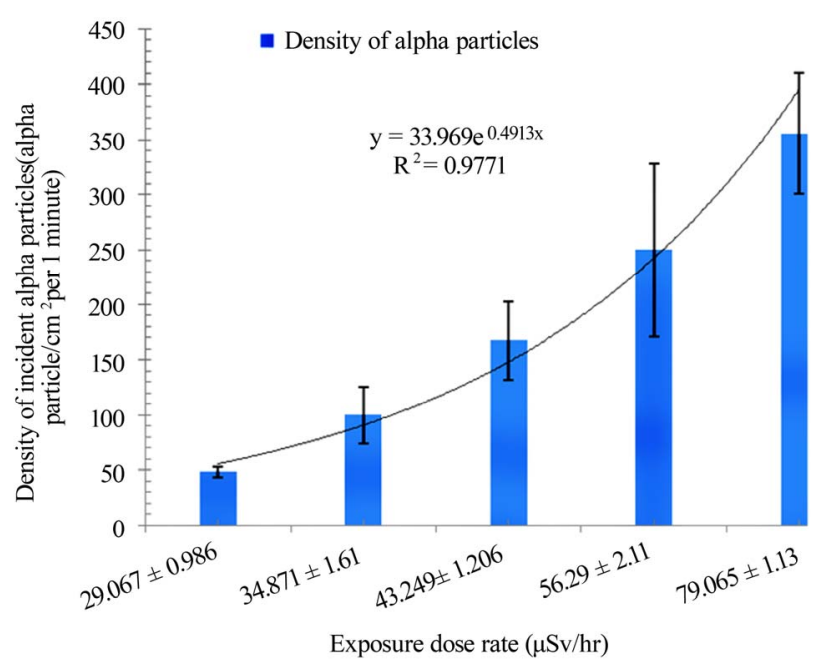

Figure 2. Equivalent relationships between alpha track density and the average exposed dose rate.

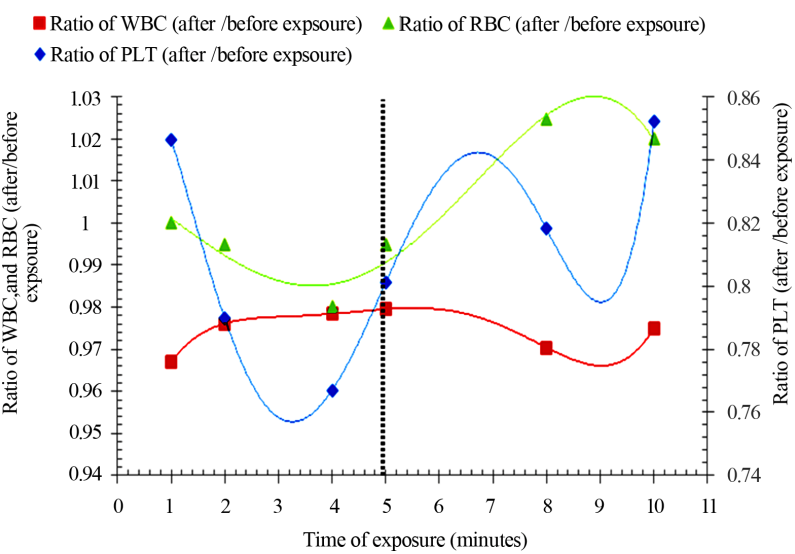

Figure 3. Relative changes of the leukemia blood components (PLT, WBC, and RBC) before and after exposure of $1100 \mu \mathrm{Sv} / \mathrm{hr}$ (Male: 16 year).

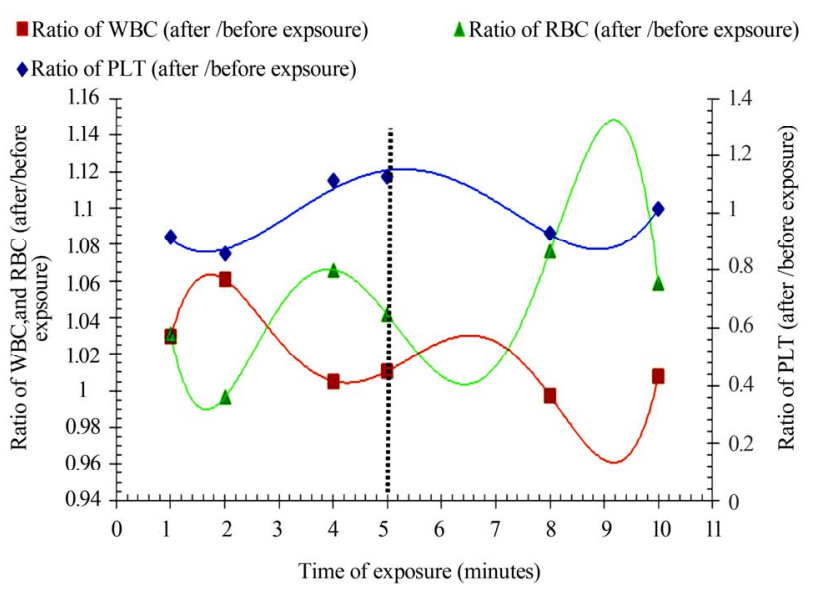

Figure 4. Relative changes of the leukemia blood components (PLT, WBC, and RBC) before and after exposure of 1100 HSv/hr (Female: 17 year).

This means that the time of exposure lead to change density of PLT, WBC, and RBC relativity. Thus, damage rate of cancer cells (more radiosensitive than normal cells) due to the ionizing get the maximum rates for the optimum time of exposure.

Optimum exposed dose rate $(\mu \mathrm{Sv} / \mathrm{hr})$ at the optimum time of exposure ( 5 minutes) has been investigated for 10 samples of males and females, and the results are listed in Tables 3 and 4. Cancer cells of exposed leukemia blood samples at $\mathrm{t}=5$ minutes were the more effects than the health cells. This is due to high density of the free radicals.

We note that the effects occurring in red blood cells adversely affected the white blood cells; this is in agreement with the basic principle of haematology and radiation casualties [20,21].

The percentage of the impact of radiation in red blood cells is unlike of its effect on white blood cells, and PLT relatively. Clearly, at the low-dose rate of $29.06 \pm 0.98$ 
Table 3. Data about effects of expose dose rate on the leukemia blood components for the male.

\begin{tabular}{|c|c|c|c|c|c|c|c|}
\hline \multirow[b]{2}{*}{$\begin{array}{l}\text { Exposure dose } \\
\text { rate } \mu \mathrm{Sv} / \mathrm{hr}\end{array}$} & \multicolumn{2}{|c|}{ PLT } & \multicolumn{2}{|c|}{ WBC } & \multicolumn{2}{|c|}{$\mathrm{RBC}$} & \multirow[b]{2}{*}{$\begin{array}{l}\text { Age/ } \\
\text { years }\end{array}$} \\
\hline & $\begin{array}{c}\text { B.I } \\
\text { PLT } \\
10^{3} / \mu \mathrm{L}\end{array}$ & $\begin{array}{c}\text { A.I } \\
\text { PLT } \\
10^{3} / \mu \mathrm{L}\end{array}$ & $\begin{array}{c}\text { B.I } \\
\text { WBC } \\
10^{3} / \mu \mathrm{L}\end{array}$ & $\begin{array}{c}\text { A.I } \\
\text { WBC } \\
10^{3} / \mu \mathrm{L}\end{array}$ & $\begin{array}{c}\text { B.I } \\
\text { RBC } \\
10^{6} / \mu \mathrm{L}\end{array}$ & $\begin{array}{c}\text { A.I } \\
\text { RBC } \\
10^{6} / \mu \mathrm{L}\end{array}$ & \\
\hline $79.10 \pm 1.13$ & 77 & 67 & 66 & 72 & 4.01 & 3.76 & 17 \\
\hline $56.26 \pm 2.11$ & 15 & 14.77 & 62.3 & 67 & 3.19 & 3.1 & 22 \\
\hline $43.25 \pm 1.20$ & 127 & 142 & 44 & 50 & 2.88 & 3.6 & 29 \\
\hline $34.85 \pm 1.61$ & 98 & 99 & 73 & 71 & 3.3 & 3.8 & 38 \\
\hline $29.06 \pm 0.98$ & 21 & 19 & 20.6 & 21.44 & 4.53 & 4.22 & 39 \\
\hline
\end{tabular}

Table 4. Data about effects of expose dose rate on the leukemia blood components for the female.

\begin{tabular}{|c|c|c|c|c|c|c|c|}
\hline \multirow[b]{2}{*}{$\begin{array}{l}\text { Exposure dose } \\
\text { rate } \mu \mathrm{Sv} / \mathrm{hr}\end{array}$} & \multicolumn{2}{|c|}{ PLT } & \multicolumn{2}{|c|}{ WBC } & \multicolumn{2}{|c|}{$\mathrm{RBC}$} & \multirow[b]{2}{*}{$\begin{array}{l}\text { Age/ } \\
\text { years }\end{array}$} \\
\hline & $\begin{array}{c}\text { B.I } \\
\text { PLT } \\
10^{3} / \mu \mathrm{L}\end{array}$ & $\begin{array}{c}\text { A.I } \\
\text { PLT } \\
10^{3} / \mu \mathrm{L}\end{array}$ & $\begin{array}{c}\text { B.I } \\
\text { WBC } \\
0^{3} / \mu \mathrm{L}\end{array}$ & $\begin{array}{c}\text { A.I } \\
\text { WBC } \\
10^{3} / \mu \mathrm{L}\end{array}$ & $\begin{array}{c}\text { B.I } \\
\text { RBC } \\
10^{6} / \mu \mathrm{L}\end{array}$ & $\begin{array}{c}\text { A.I } \\
\text { RBC } \\
10^{6} / \mu \mathrm{L}\end{array}$ & \\
\hline $79.10 \pm 1.13$ & 68 & 56 & 45 & 55 & 2.98 & 2.65 & 16 \\
\hline $56.26 \pm 2.11$ & 71 & 65 & 52 & 60 & 4.98 & 4.55 & 23 \\
\hline $43.25 \pm 1.20$ & 101 & 120 & 80 & 71 & 3.61 & 4.78 & 30 \\
\hline $34.85 \pm 1.61$ & 53 & 55 & 68 & 62 & 4.11 & 5 & 37 \\
\hline $29.06 \pm 0.98$ & 34 & 30 & 18 & 19 & 5 & 4.33 & 40 \\
\hline
\end{tabular}

$\mu \mathrm{Sv} / \mathrm{hr}$, and high-dose rate $79.10 \pm 1.13 \mu \mathrm{Sv} / \mathrm{hr}$, the behavior of PLT and RBC are same (reduced relativity after exposure), and they have oppositely behaviors with WB C. At the dose rate $43.25 \pm 1.20 \mu \mathrm{Sv} / \mathrm{hr}$, the ratio of PLT and $\mathrm{RBC}$ go to the high ratio for both male and female (see Figures 5 and 6). Thus, $43.33 \mu \mathrm{Sv} / \mathrm{hr}$ considered as an optimum exposed dose rates for PLT, WBC, and RBC. The changing reverse of the blood components of the incident radiation, due to the radiosensitive of these components are varied. As well as, ionization for cancer cells is more than the normal cells. Therefore, at the high-dose rate $(79.10 \pm 1.13 \mu \mathrm{Sv} / \mathrm{hr})$ ratio of PLT and $\mathrm{RBC}$ after exposure increased too. This is because the damage rate is included healthy cells as well. Thus, for that reason optimum dose rate to make damage of the cancer cells and to avoid normal (health) cells considered as an important part of this research. The impacts of exposed low dose on the density of PLT, WBC and RBC for the healthy blood samples (male; 24 years) are reported by previous work [6], and as shown in Figure 7. Clearly the behaviours of PLT, WBC, and RBC for healthy blood samples are different than leukemia blood samples. This is because of high rate of ionizations within an irradiation of leukemia blood samples. This means that the rates of ionizations are different for healthy and leukemia blood samples. On the other hand, maximum exposed dose rate at the healthy case was not given up to the density of RBC before irradiation. And for providing a more clarify of how to change the values for the PLT,
WBC, and RBC with the rate of radiation, the proportion has changed to the duties before and after irradiation was a factor of excellence.

This causes the greatest damage to the blood cells because the alpha particles are heavy ions. Therefore, the alpha particles will lose most of their energy within a short distance in their trajectory during irradiation. This causes ionization of atoms of blood cell through the method of atomic displacements. The results are in agreement with the basic principles of the phenomena of biological radiation interaction [20,21].

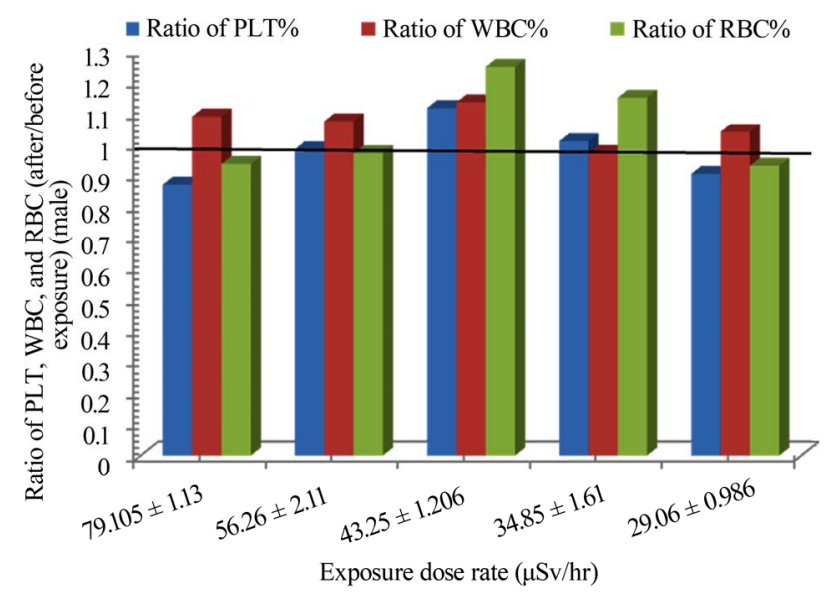

Figure 5. Variations of the ratio of PLT, WBC, and RBC after/before exposure to various dose rates for male leukemia blood samples. 


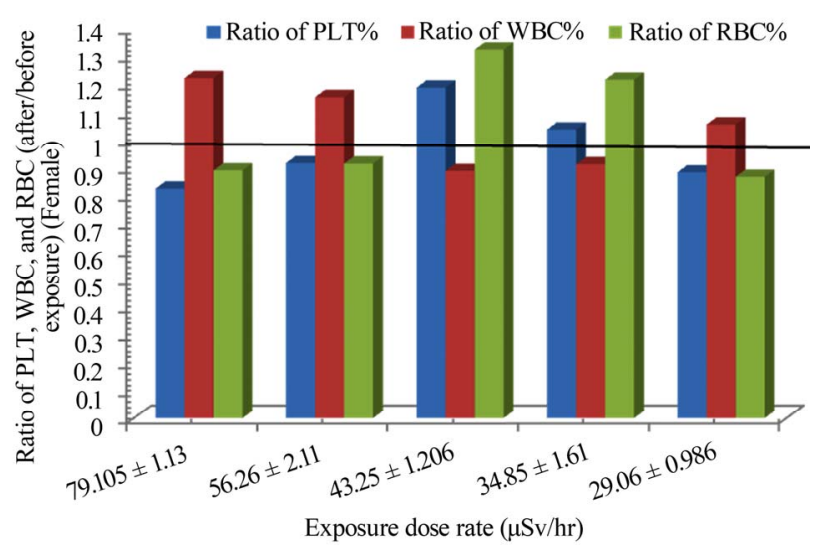

Figure 6. Variations of the ratio of PLT, WBC, and RBC after/before exposure to various dose rates for female leukemia blood samples.

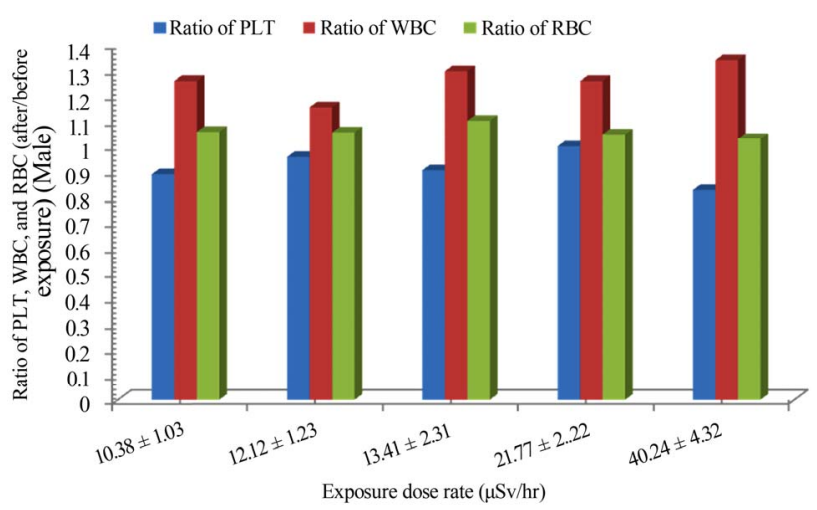

Figure 7. Variations of the ratio of PLT, WBC, and RBC after/before exposure to various dose rates for male of healthy blood samples [ismail 2011].

\section{Conclusions}

Radiation exposure of leukemia blood samples and its impacts on the density of RBC, WBC, and PLT has been investigated for 12 patients (six males and six females). In the first part of this research, density of the accumulation of alpha particle on the surface of leukemia blood samples varies exponentially with the exposed dose rate. Optimum values of time of exposure and exposure dose rate to make sufficient changes in blood components (PLT, WBC, and RBC) were found equal to 5 minutes and $43.33 \mu \mathrm{Sv} / \mathrm{hr}$, respectively.

The density of WBC was inversely changed with RBC and PLT for leukemia blood samples. However, for healthy blood sample's density of RBC was the approximately constant opposite of its density in the case of leukemia blood sample. As well as, optimum exposed dose rate for $\mathrm{WBC}$ is different than its value for RBC.

\section{Acknowledgements}

We would like to thanks Physics Department-Nuclear
Lab./Science College, Salahaddin University-Erbil for their cooperation with 226Ra source. As well as, the authors also wish to thank all laboratory staffs inside Nanakali Hospital for their cooperation.

\section{REFERENCES}

[1] R. J. Dufrain, L. G. Littlefield and E. E. Joiner, "Human Cytogenetic Dosimetry: A Dose Response Relationship for Alpha Particle Radiation from 241Am," Health Physics, Vol. 37, No. 3, 1979, pp. 279-289. doi:10.1097/00004032-197909000-00002

[2] NRCNA (National Research Council of the National Academies), "Health Risks from Exposure to Low Levels of Ionizing Radiation,” Beir VII Phase 2, 2006.

[3] R. W. Field, "Radon: An Overview of Health Effects," Encyclopedia of Environmental Health, Vol. 23, 2011, pp. 745-753.

[4] M. E. Gaulden, "Biological Dosimetry of Radionuclide and Radiation Hazards," Journal of Nuclear Medicine, Vol. 24, No. 2, 1983, pp. 160-164.

[5] R. M. Anderson, S. J. Marsden, E. G. Wright, M. A. Kadhim, D. T. Goodhead and C. S. Griffin, "Complex Chromosome Aberrations in Peripheral Blood Lymphocytes as a Potential Biomarker of Exposure to High-LET Alpha-Particles," International Journal of Radiation Biology, Vol. 76, No. 1, 2000, pp. 31-42. doi:10.1080/095530000138989

[6] A. H. Ismail and M. S. Jaafar, "Interaction of Low-Intensity Nuclear Radiation Dose with the Human Blood: Using the New Technique of CR-39NTDs for an in Vitro Study," Applied Radiation and Isotopes, Vol. 69, No. 3, 2011, pp. 559-566. doi:10.1016/j.apradiso.2010.11.004

[7] IAEA (International Atomic Energy Agency), "Effects of Ionizing Radiation on Blood and Blood Components: A Survey," TECDOC-934, 1997.

[8] ICRP (International Commission on Radiological Protection), "Recommendation of the International Commission on Radiological Protection," ICRP Publication 60, 1990, pp. 1-3.

[9] K. Cureton, B. Phillip, H. Patricia, N. Hillary, V. Susan and Z. Linda, "Sex Difference in Maximal Oxygen Uptake; Effect of Equating Hemoglobin Concentration," European Journal of Applied Physiology, Vol. 54, No. 6, 1986, pp. 656-660. doi:10.1007/BF00943356

[10] A. A. Edwards, R. J. Purrott, S. J. Prosser and D. C. Lloyd, "The Induction of Chromosome Aberrations in Human Lymphocytes by Alpha-Radiation," International Journal of Radiation Biology \& Related Studies in Physics, Chemistry \& Medicine, Vol. 38, No. 1, 1980, pp. 83-91.

[11] V. Z. Hamza, P. R. V. Kumar, R. K. Jeevanram, R. Santanam and B. Danalaksmi, "A Simple Method to Irradiate Blood Cells in Vitro with Radon Gas," Radiation Protection Dosimetry, Vol. 130, No. 3, 2008, pp. 343-350. doi: $10.1093 / \mathrm{rpd} / \mathrm{ncn} 060$

[12] T. Kenner, "Review: The Measurement of Blood Density and Its Meaning," Basic Research in Cardiology, Vol. 84, No. 2, 1989, pp. 111-124. doi:10.1007/BF01907921 
[13] V. Valković, "Radiation Safety," Radioactivity in the Environment, Vol. 23, 2000, pp. 259-303. doi:10.1016/B978-044482954-2/50006-X

[14] M. Hada, W. U. Honglu and F. A. Cucinotta, "mBAND Analysis for High- and Low-LET Radiation Induced Chromosome Aberrations: A Review," Mutation Research/ Fundamental and Molecular Mechanisms of Mutagenesis, 2011.

[15] K. Jefferson, "Radiation Worker I Training Study Guide," Lab Radiation Control Department, 2010, pp. 1-73.

[16] G. Sgouros, "Alpha-Particles for Targeted Therapy," Advanced Drug Delivery Reviews, Vol. 60, No. 12, 2008, pp. 1402-1406. doi:10.1016/j.addr.2008.04.007

[17] N. Joseph and J. Phalen, "Online Radiology Continuing Education for Radiology Professionals. Part 2. Biological Effects of Irradiation," 2010. http://www.ceessentials.net/article3.html

[18] D. C. Lloyd, R. J. Purrott, G. W. Dolphin, D. Bolton, A.
A. Edwards and M. J. Corp, "The Relationship between Chromosome Aberrations and Low LET Radiation Dose to Human Lymphocytes," International Journal of Radiation and Biology, Vol. 28, No. 1, 1975, pp. 75-90. doi:10.1080/09553007514550781

[19] S. C. Mehta, "Health Risks of Low Level Radiation Exposures: A Review," Indian Journal of Nuclear Medicine, Vol. 20, No. 2, 2005, pp. 29-41.

[20] J. Pohl-Ruling and E. Pohl, "Method for Alpha Irradiation of Blood Cultures with Short-Lived Radon-222 Decay Products," Mutation Research, Vol. 234, No. 5, 1990, pp. 43-45. doi:10.1016/0165-1161(90)90029-N

[21] J. Pohl-Ruling, H. Lettner, W. Hofmann, P. Eckl, O. A Haas, et al., "Chromosomal Aberrations of Blood Lymphocytes Induced in Vitro by Radon-222 Daughter $\alpha$-Irradiation," Mutation Research, Vol. 449, No. 1-2, 2000, pp. 7-19. doi:10.1016/S0027-5107(00)00009-9 